\title{
Penghitungan Biaya Satuan pada Instalasi Rawat Jalan di Rumah Sakit X Jambi menggunakan Metode Step Down
}

\author{
Unit Cost of Outpatient Unit Using \\ Step Down Method at Hospital X in Jember
}

\author{
Susilo Wulan ${ }^{1}$, Ade Herman Surya Direja ${ }^{2}$, Dian Reflisiani ${ }^{3}$ \\ ${ }_{1}^{1}$ Prodi Kesehatan Masyarakat STIKES Tri Mandiri Sakti Bengkulu, \\ ${ }^{2}$ Prodi IImu Keperawatan STIKES Tri Mandiri Sakti Bengkulu \\ ${ }^{3}$ Prodi Kebidanan D IV STIKES Tri Mandiri Sakti Bengkulu \\ Korespondensi: Susilo Wulan \\ e-mail:wulan_susilo@yahoo.com
}

\begin{abstract}
Abstrak
Tanggung jawab Rumah sakit adalah memberikan pelayanan yang berkualitas dan terjangkau bagi masyarakat, sehingga penentuan tarif dengan perhitungan biaya aktual sangat diperlukan sebagai dasar pengambilan keputusan yang lebih presisi. Penelitian ini bertujuan untuk menghitung biaya satuan dan analisis perbandingan biaya antar unit di instalasi rawat jalan menggunakan metode step down. Penelitian ini merupakan bagian dari partial economic evalution yaitu hanya memotret deskripsi biaya dari suatu objek (cost object) tanpa membandingkan luaran layanan dari unit yang di analisis. Tahapan analisis data meliputi identifikasi sumber dari pusat biaya dengan menentukan final cost, intermediate cost dan indirect cost, tahap kedua yaitu mengidentifikasi dan menghitung biaya investasi, biaya operasional dan biaya pemeliharaan. Hasil penelitian menujukkan biaya satuan tertinggi terdapat di poli gigi dan mulut sebesar Rp 621.100,99/kunjungan sedangkan biaya satuan terendah di poli penyakit dalam yaitu sebesar Rp 214.307,51/kunjungan. Diharapkan hasil penelitian ini dapat menjadi pertimbangan dalam perubahan ataupun penyesuaian tarif layanan dan menjadikan bahan evaluasi pada poli rawat jalan agar lebih efisien dalam pengelolaanya.

kata kunci: unit cost, metode step down, rawat jalan.
\end{abstract}

\begin{abstract}
Hospital has a responsibility to provide quality and affordable health care to the community. Therefore, determining tariffs by calculating the actual cost is very important, especially for internal stakeholders in undergoing cost analysis, performance evaluation and decision making, including tariff negotiation with external stakeholders. This research objective is to calculate unit costs and comparatively analyzing costs between units in an outpatient installation using the step-down method. This research used a partial economic evaluation which only portrays the description of cost object without comparing the output from the analyzed unit. The stages of data analysis include identifying the resource of cost center by firstly determining the final cost, intermediate cost and indirect cost, the second stage is identifying and calculating investment cost, operational cost, and maintenance costs, the third stage is determining the allocation basis, and the fourth stage is calculating the total cost. The highest unit cost occurs in dental poly at Rp.621.100,99/visit, while the lowest unit cost is in internal medicine which is Rp.241.307,51/visit. It is hoped that the results of this study can be taken into consideration in the changes made by service rates and making evaluation materials on outpatient care so that they are more efficient in their management.

Keywords: unit cost, step down method, outpatient.
\end{abstract}

\section{Pendahuluan}

Rumah sakit sebagai salah satu fasilitas pelayanan kesehatan memiliki peran strategis dalam meningkatkan derajat kesehatan masyarakat dengan memberikan pelayanan kuratif dan rehabilitatif kepada pasien. Rumah sakit dengan status Pola Pengelolaan Keuangan Badan Layanan Umum Daerah (PPK-BLUD) harus mengutamakan pelayanan terbaik untuk masyarakat dalam menyediakan jasa pelayanan dan bukan hanya bertujuan untuk mendapatkan keuntungan (Sugiyarti, et al, 2013). Hal ini membuat rumah sakit harusmenjalankan operasional secaraefektif dan efisien.
Dalam merencanakan anggaran pendapatan dan belanja rumah sakit diperlukan informasi mengenai besarnya biaya satuan (unit cost) dari setiap unit pelayananan. Rumah sakit yang berstatus PPK-BLUD memiliki aturan tersendiri untuk menentukan besaran tarif yang ditentuntukan berdasarkan perhitungan unit cost sesuai dengan Peraturan Pemerintah nomor23 tahun 2005 dan Peraturan Menteri Dalam Negeri nomor 61 tahun 2007. Imbalan atas barang/jasa layananan yang diberikan ditetapkan dalam bentuk tarif yang disusun atas perhitungan biaya per unit layanan atau 
hasil per investasi dana, serta perhitungan tarif layanan harus mempertimbangkan aspekaspek sepertikontiunitas dan pengembangan masyarakat, daya beli masyarakat, asas keadilan dan kepatutan dan kompetisi yang sehat (Ambarriani, 2012).

Penghitungan actual cost sebagi dasar penentuan tarif sangat penting dan menjadi tantangan terhadap keberlangsungan sistem pentarifan yang diberlakukan dalam INA-CBGs. Perhitungan unit cost di rumah sakit digunakan untuk membantu mengindentifikasi kebutuhan sumber daya dalam jasa pelayanan, membantu manajemen rumah sakit untuk keperluan analisis biaya, menentukan alokasi anggaran secara efisien, menentukan tindakan kuratif terbaik dan memastikan dana yang memadai untuk setiap layanan (Conteh and Walker, 2004). Infoasi unit cost juga dibutuhkan untuk pengambilan keputusan taktis dan strategik serta sebagai alat bernegosiasi dengan pihak eksternal termasuk pemerintah (Hansen and Maryanne, 2005).

Pehitungan unit cost menggunakan metode step down (double distribution method) merupakan salah satu metode yang digunakan dalam analisis biaya khususnya dalam mengalokasikan biaya unit penunjang kepada unit produksi. Pemilihan metode step down karena relatif sederhana dan praktis untuk diaplikasikan (Conteh and Walker, 2004). Dengan analisis biaya ini selanjutnya akan diperoleh biaya aktual/rill sebagai dasar dalam penetapan tarif pelayanan di rumah sakit RSUD X Jambi merupakan RS milik pemerintah tipe $C$ dengan status BLUD, memiliki tugas sesuai dengan ketentuan yang diberikan oleh Bupati Kabupaten Sarolangun.

Dalam rangka memberikan penetapan tarif terhadap pelayanan kesehatan mengacu pada Peraturan Daerah Kabupaten Sarolangun Nomor 32 tahun 2015 tentang perubahan atas peraturan Bupati Nomor 56 tahun 2013 tentang tarif pelayanan kesehatan selain kelas III pada RSUD X Jambi yang telah menetapkan pola pengelolaan keuangan badan layanan umum daerah. Jumlah kunjungan pasien tahun 2015 meliputi: kunjungan rawat inap sebanyak 6.431 pasien dengan jumlah hari rawat 20.387; jumlah pasien rawat jalan (poliklinik dan UGD) 21.334 pasien; jumlah pemeriksaan pelayanan penunjang laboratorium dan radiologi mas- ing-masing 14.763 dan 5.724; serta pelayanan intermediate OK, ICU, NICU, Bank Darah, Fisioterapi dan Farmasi.

Di RSUD X Jambi, masih ditemukan permasalahan dalam menerapkan penghitungan unit cost yang menyebabkan penentuan tarif pelayanan yang dibebankan ke pasien tidak menutup biaya investasi, biaya operasional dan biaya pemeliharaan. Dasar penetapaan RSUD X Jambi belum menggunakan metode perhitungan biaya satuan (unit cost), oleh karena itu diperlukan kajian mengenai analisis biaya RS dalam menghitung unit cost dengan menggunakan metode step down (double distribution) dalam mendukung peningkatan efisiensi dan efektivitas manajemen keuangan RSUD X Jambi.

\section{Metode}

Analisis biaya yang dilakukan dalam studi ini merupakan bagian dari partial economic evaluation dimana unit biaya yang dianalisis tidak membandingkan luaran layanan dari beberapa objek biaya yang menjadi fokus penilaian. Data primer yang dikumpulkan berupa seluruh kegiatan operasional selama tahun 2015 selanjutnya akan diolah dengan menggunakan pendekatan step down. Pengumpulan data dilakukan melalui penilaian dokumentasi, observasi dan wawancara. Teknik penyajian data meliputi editing, tabulasi data, dan penyajian data.

Pendekatan step down dipilih dengan mempertimbangkan kendala di rumah sakit seperti ketersediaan data berupa sumberdaya (resources) termasuk biaya dan total penggunaan layanan yang tidak lengkap sehingga pendekatan penghitungan biaya satuan yang paling sederhana dan praktis digunakan adalah step down. Tahapan-tahapan metode step down (double distribution) terdiri dari:

a. Identifikasi cost centers,

Agar biaya dapat di alokasikan dengan benar, cost centers di unit rawat jalan diidentifikasi menjadi indirect cost, intermediate cost dan final cost. Indirect cost merupakan layanan umum dalam bentuk overhead dan tidak terkait langsung dengan perawatan pasien dan pelayanan intermediate seperti biaya administrasi dan manajemen, biaya transportasi, biaya laundry dan biaya layanan pendukung. Intermediate cost merupakan departemen yang memberikan dukungan diagnostik pada unit rawat jalan dan dikelola terpisah, sedangkan final cost merupakan 
final level dari pusat biaya karena merupakan titik akhir dari kegiatan produksi dalam hal ini adalah unit rawat jalan.

b. Pendistribusian indirect cost

Yaitu tahap mengalokasikan semua indirect cost ke unit rawat jalan. Dasar alokasi dalam penelitian ini mengadopsi dari (Shepard, Hodgkin and Anthony, 1998). Pendekatan step down mempertimbangkan hubungan antar unit penunjang. Dalam hal ini indirect cost dialirkan ke sesama unit di indirect, ke sesama unit intermediate clinical care dan unit unit rawat jalan sebagai final product dengan dasar alokasi yang sudah ditetapkan. Indirect cost yang paling banyak memberikan kontribusi di letakkan pada urutan tertinggi dalam susunan alokasi biaya, sedangkan yang memiliki kontribusi terkecil diletakkan di urutan terbawah. Indirect cost yang paling banyak berkontriubusinya setelah dialokasikan biaya aslinya maka biaya ini akan ditutup. Artinya unit ini tidak akan mendapat alokasi dari unit di peringkat yang bawah.

c. Menghitung total cost

Total cost dihitung dengan menjumlahkan direct cost dan indirect cost. Direct cost teridri dari biaya asli yang terjadi di unit rawat jalan terdiri dari biaya personel, investasi gedung, peralatan medis dan non medis, biaya farmasi, biaya lab dan UTD, serta biaya radiologi dan fisioterapi. Sedangkan indirect cost terdiri dari biaya administrasi dan manajemen, biaya transportasi, biaya laundry dan layanan pendukung.

d. Menghitung unit cost

Untuk dapat menghitung unit cost maka diperlukan aktivitas data secara detail setiap kunjungan atau jenis penyakit karena informasi ini sangat berguna dalam penghitungan unit analisis. Untuk menyajikan perhitungan mengubah total cost menjadi unit cost diperlukan dua informasi penting yaitutotal biaya dan unit output. Sehingga perhitungan unit cost diperoleh dari pembagaian total cost dengan denomerator berupa outputnya.

\section{Hasil}

Langkah awal dalam dalam melakukan analisis biaya adalah dengan melakukan penelusuran terhadap data pengeluaran/belanja RS tahun 2015 untuk selanjutnya dilakukan identifikasi biaya-biaya mana saja yang terkait dengan unit rawat jalan. Unit rawat jalan sebagai unit akhir dari proses produksi, maka hasil identifikasi biaya asli adalah sebagai berikut:

a. Biaya personel, merupakan biaya yang berhubungan dengan sumber daya manusia terdiri dari biaya gaji, jasa medis dan honor lainnya, seragam, akomodasi dan perjalanan dinas pada pegawai yang unit rawat jalan. Jumlah pegawai yang bertugas di unit rawat jalan terdiri dari 9 dokter spesialis, 2 dokter umum, dan 23 perawat dan bidan. Total pengeluaran yang berhubungan dengan biaya personal di unit rawat jalan selama tahun 2015 adalah sebesar Rp 2.715.981.363

b. Biaya investasi gedung yang disertakan dalam proses analisis diestimasi melalui data luas gedung dan nilai perolehan asset. Berdasarkan informasi tersebut selanjutnya dihitung nilai tahunan biaya investasi menggunakan rumus AIC (Annual Investment Cost). Hasil perhitungan nilai investasi gedung rawat jalan yang disetahunkan adalah sebesar Rp 9.855.967 yang dialokasikan berdasarkan luas lantai.

c. Biaya investasi peralatan medis diestimasi berdasarkan data peralatan medis (Bed/TT dan Non Bed/TT) termasuk nilai perolehan yang didapatkan dari bagian sarana dan prasarana dan pengurus barang di RS serta observasi langsung pada masing-masing poli. Peralatan medis yang tahun perolehannya lebih dari 5 tahun akan dikeluarkan dalam penghitungan harga perolehan. Hasil perhitungan nilai investasi peralatan medis di unit rawat jalan yang disetahunkan adalah sebesar Rp 35.510.362

d. Biaya investasi peralatan non medis terdiri atas furniture, peralatan kantor, Ac/Kipas angin dan lain lain yang ada di tiap-tiap poli rawat jalan. Hasil penghitungan nilai investasi peralatan non medis yang disetahunkan sebesar Rp 14.232 .862

e. Biaya farmasi. unit farmasi merupakan unit penunjang yang memberikan dukungan pada unit rawat jalan. Menurut catatan dari unit farmasi biaya bahan habis pakai dan obat untuk unit rawat jalan selama tahun 2015 adalah sebesar Rp 358.435.345

Biaya unit penunjang lainnya yang terkait dengan unit rawat jalan adalah unit laboratorium dan UTD serta unit radiologi dan fisioterapi. Beberapa pasien rawat jalan memanfaatkan jasa layanan di dua unit penunjang tersebut. hasil identifikasi biaya menunjukkan biaya sebesar Rp 466.487.956 dan Rp 238.652 .940 


\section{Identifikasi Biaya tidak langsung}

Dalam penelitian ini biaya tidak langsung dikategorikan dalam lima kategori yaitu biaya administrasi dan manajemen, biaya trasnportasi, biaya laundry, biayalayanan pendukung layanan pendukung dan biaya instalasi gizi. Biaya-biaya tersebut diperoleh dari daftar belanja RS selama tahun 2015 yang kemudian dialokasikan ke tiap pusat biaya melalui dasar alokasi terentu (tabel 1).

a. Biaya administrasi dan Manajemen di instalasi rawat jalan sebesar Rp 488.780.855 terdiri atas alokasi biaya utilitas (air, listrik, telpon, sewa, listrikdangenset, dan operasional lainnya).

b. Biaya transportasi di instalasi rawat jalan sebesar Rp 82.588.479 terdiri atas biaya jasa service kendaraan, pengeluaran bahan bakar, pelumas dan spare part serta biaya pemeliharaan kendaraan.

c. Biaya laundry di instalasi rawat jalan sebesar Rp 5.075.160 terdiri atas biaya deterjen, perlengkapan mencuci lainnya serta peralatan rumah tangga, gaji pegawai dan seragam di unit laundry. Data ini diperoleh dari catatan RS atas permintaan kebutuhan unit laundry dan barang yang diterima yaitu jumlah $\mathrm{kg}$ linen yang diterima dari unit rawat jalan.

d. Biaya layanan pendukung layanan pendukungsebesar Rp 529.049.614 terdiri atas biaya yang terjadi di unit penunjang seperti kebutuhan gas medic, IPSRS, cleaning service, security dan kamar jenazah. Alokasi layanan pendukung layanan pendukung berdasarkan jumlah SDM.

Berdasarkan hasil penelitian bahwa instalasi gizi hanya bertanggung jawab menyediakan asupan makanan kepada pasien rawat inap, sehingga dalam hal ini tidak ada alokasi biaya instalasi gizi pada unit rawat jalan. Hasil identifikasi terhadap biaya asli dan juga biaya tidak langsung merupakan informasi total biaya yang terjadi di unit rawat jalan untuk selanjutnya akan di alokasikan ke poli-poli yang ada di RS.

Berdasarkan tabel 2 diperoleh informasi total cost di instalasi rawat jalan RSUD X Jambi adalah sebesar Rp 4.941.650.712 yang merupakan hasil penjumlahan biaya asli dan alokasi biaya tidak langsung.

\section{Dasar perhitungan dengan pendekatan step-} down

Biaya tidak langsung (overhead centers) yang paling banyak kontribusinya setelah dialokasikan ke biaya asli maka biaya ini akan ditutup. Artinya unit tersebut tidak akan mendapat alokasi lagi dari unit di peringkat yang terbawah. Ada beberapa langkah yang dilakukan yaitu langkah pertama adalah overhead centres (indirect) akan didistribusikan ke intermediate clinical care dan patient care (direct), dengan cara:

1. Mendistribusikan biaya tidak langsung yang kontribusinya terbesar ke terkecil berterurutturut adalah biaya administrasi dan manajemen, biaya laundry, biaya layanan pendukung dan biaya transportasi

2. Biaya administrasi dibagi secara adil berdasarkan aktivitas data jumlah SDM. Dari daftar nama staf/karyawan, persentasi biaya administrasi dapat dipecah menjadi: 4\% laundry, 59 \% layanan pendukung dan seterusnya. Artinya setiap pecahan persentase telah dibagi, kemudian total biaya administrasi akan terdistribusi dengan sendirinya ke pusat biaya laundry, layanan pendukung dan seterusnya. Dalam hal ini pusat biaya administrasi telah diserahkan semuanya sisanya kepada pusat biaya berikutnya, sehingga $\mathrm{Rp}$ 488.785.855 sekarang telah diserap. Pusat biaya laundry sekarang memperoleh tambahan Rp 19.551.234 lebih tinggi dari biaya asli yang telah ditetapkan sebelumnya, dan seterusnya sampai ke final produk pada masing-masing poli.

Proses alokasi kedua adalah biaya laundry. Biaya laundry tidak mudah untuk ditelusuri, sementara semua biaya laundry dapat dibagi secara adil kepada pusat biaya Rumah sakit berdasarakan jumlah kg linen tiap pusat biaya. Seperti dalam biaya administrasi, biaya laundry juga dialokasikan tanpa sisa ke cost centre berikutnya sehingga Rp 24.626.394 sekarang telah diserap. Pusat biaya layanan pendukung memperoleh tambahan $\mathrm{Rp}$ 4.825.279 lebih tinggi dari biaya asli yang diterapkan sebelumnya hasil alokasi dari pusat biaya administrasi dan laundry. Proses alokasi ke tiga dan keempat yaitu alokasi biaya layanan pendukung dan tranportasi denga langkah yang sama pada pengalokasian sebelumnya. Langkah kedua adalah mendistribusikan biaya intermediate clinical care ke final product dengan cara:

1. Biaya asli dan alokasi biaya tidak langsung pada unit farmasi, laboratorium dan UTD serta radiologidanfisioterapi selanjutnya akan dialokasikan kepada produk akhir, yaitu polipoli yang ada di instalasi rawat jalan RSUD 
Tabel 1.DasarAlokasi

\begin{tabular}{|c|c|c|c|c|c|c|c|c|c|}
\hline \multirow{2}{*}{$\begin{array}{l}\text { Dasar } \\
\text { Alokasi }\end{array}$} & \multicolumn{7}{|c|}{ Indirect cost ke Intermediate dan Direct Cost } & \multicolumn{2}{|c|}{$\begin{array}{l}\text { Intermediate Cost } \\
\text { Ke Direct Cost }\end{array}$} \\
\hline & $\begin{array}{l}\text { Ad- } \\
\text { m\&Mnj }\end{array}$ & $\begin{array}{l}\text { Trans- } \\
\text { portasi }\end{array}$ & Catering & Laundry & Kebersihan & $\begin{array}{l}\text { Pemeli- } \\
\text { haraan }\end{array}$ & Farmasi & $\begin{array}{l}\text { Labora- } \\
\text { torium }\end{array}$ & $\begin{array}{c}\text { Ra- } \\
\text { diolo- } \\
\text { gy }\end{array}$ \\
\hline Kunjungan & & & & & & & & $\mathrm{X}$ & $\mathrm{X}$ \\
\hline $\begin{array}{l}\text { Biaya } \\
\text { langsung }\end{array}$ & $\mathrm{X}$ & $\mathrm{X}$ & & & $\mathrm{X}$ & $\mathrm{X}$ & & & \\
\hline Hari Rawat & & & $\mathrm{X}$ & $\mathrm{X}$ & & & $\mathrm{X}$ & X & $\mathrm{X}$ \\
\hline $\begin{array}{l}\text { Estimasi } \\
\text { Riil }\end{array}$ & & $\mathrm{X}$ & & $\mathrm{X}$ & & & & & \\
\hline $\begin{array}{l}\text { Estimasi } \\
\text { Karyawan }\end{array}$ & & & & & & & $\mathrm{X}$ & $\mathrm{X}$ & $\mathrm{X}$ \\
\hline Luas lantai & & & & $\mathrm{X}$ & $\mathrm{X}$ & $\mathrm{X}$ & & & \\
\hline Jumlah TT & & & & & & & & & \\
\hline Biaya Gaji & $\mathrm{X}$ & $\mathrm{x}$ & $\mathrm{X}$ & & & & & & \\
\hline $\begin{array}{l}\text { Jumlah } \\
\text { SDM }\end{array}$ & $\mathrm{X}$ & & $\mathrm{X}$ & & $\mathrm{X}$ & $\mathrm{X}$ & & & \\
\hline
\end{tabular}

Adopted: Shepard et al. 1998

Tabel 2 Identifikasi biaya asli dan biaya tidak langsung unit rawat jalan

\begin{tabular}{llc}
\hline No & \multicolumn{1}{c}{ Keterangan } & Jumlah \\
\hline $1 \quad$ & Biaya Asli & \\
& a. Biaya Personel & Rp. 2.715 .981 .363 \\
& b. Investasi Gedung & Rp. 9.855 .967 \\
c. Investasi Peralatan Medis & Rp. 35.510 .362 \\
d. Investasi Peralatan Nonmedis & Rp. 14.232 .862 \\
e. Biaya Farmasi & Rp. 466.487 .956 \\
f. Biaya laboratorium dan danUTD & Rp. 358.435 .345 \\
g. Biaya Radiologi dan danFisioterapi & Rp. 238.652 .940 \\
Total Biaya Asli & Rp. 3.836.156.795 \\
AlokasiBiayaTidak Langsung & \\
a. biaya administrasi dan manajemen & Rp. 488.780 .855 \\
b. biaya transportasi & Rp. 82.588 .479 \\
c. biaya laundry & Rp. 5.075.160 \\
d. layanan pendukunglayanan pendukung & Rp. 529.049 .614 \\
\hline Total alokasi biaya tidak langsung & Rp. 1.105.494.108 \\
\hline & Rp. 4.941 .650 .712 \\
\hline
\end{tabular}


$\mathrm{X}$ Jambi dengan cara yang sama pada saat mengalokasikan indirect cost ke intermediate cost.

2. Biaya farmasi mengkonsumsi porsi yang cukup signifikan dalam anggaran belanja Rumah sakit di luar gaji. Biaya farmasi terdiri atas biaya obat dan bahan medis habis pakai di unit rawat jalan menurut daftar biaya farmasi yang diperoleh dari catatan penyaluran obat kepada pasien langsung maupun pengadaan ke bangsal-bangsal. Biaya farmasi unit rawat jalan berdasarkan catatan tahun 2015 adalah sebesar Rp 358.435.345 kemudian memperoleh alokasi dari biaya tidak langsung menjadi Rp 640.141.513. Biaya ini kemudian dialokasikan ke cost center lainnya dengan berdasarkan jumlah utiliasi obat berdasarkan kunjungan.

3. Laboratorium dan UTD terdiri atas biaya operasional penggunaan reagen, bahan medis habis pakai. Setelah memperoleh alokasi dari biaya farmasi biaya laboratorium dan UTD menjadi Rp 932.470.257,85. Biaya ini kemudian dialokasikan ke cost center lainnya berdasarkan jumlah output/hasil tes. Ketiadaan beberapa catatan, aktivitas data bisa menggunakan proksi tingginya persentasi kunjungan rawat jalan. Dalam penelitian ini biaya laboratorium dan UTD dialokasikan berdasarkan jumlah kunjungan. Hal ini berlaku juga pada pusat biaya radiologi dan fisioterapi.

4. Radiologi dan Fisioterapi, terdiri atas biaya operasional penggunaan reagen, bahan medis habis pakai, penggunaan peralatan radiologi dan fisioterapi sekaligus biaya operator penggunaan alat tersebut. Setelah memperoleh alokasi dari unit farmasi dan laboratorium biaya unit radiologi dan fisioterapi menjadi Rp 561.331.611,66. Biaya ini kemudian dialokasikan ke final produk berdasarkan output radiologi dan pelayanan khusus. Sehinggar diperoleh biaya total unit pelayanan di poli-poli yang ada di instalasi rawat jalan.

Langkah selanjutnya membuat tabel rekap total biaya dan output layanan pada masing-masing poli, kemudian menghitung biaya satuan yaitu membagi total biaya dengan total output (Tabel 3).

\section{Pembahasan}

Hasil perhitungan unit cost dapat terdiri dari dua macam unit biaya yaitu yang sifatnya normatif dan aktual. Unit biaya normatif disusun dengan terlebih dahulu menghitung prediksi berapa besar biaya tetap dan biaya variabel dan membagi dengan kapasitas/output optimal yang dapat di produksi. Perhitungan unit cost yang digunakan dalam penelitian ini adalah berdasarkan data aktual. Sejalan dengan (Djuhaeni, 2009) yang menyaatakan bahwa biaya satuan (unit cost), biaya satuan yang diperoleh dari hasil analisis biaya merupakan biaya satuan aktual. Tarif yang merefleksikan biaya aktual pelayanan akan mendorong rumah sakit memenuhi kebutuhan medis yang diperlukan (Handayani et all, 2018)

Kelemahan penggunaan data aktual akan menyebabkan penghitungan yang unit cost yang undercosting maupun overcosting. Undercosting terjadi manakala suatu produk menggunakan sumberdaya yang banyak tetapi dilaporkan memiliki unit cost yang rendah, sebaliknya overcosting yaitu produk mengkonsumi sumberdaya yang sedikit tetapi mempunyai unit cost yang tinggi. Pada produk-produk yang mengalami overcost maupun undercost maka akan saling meng-adjust. Hal ini terjadi karena total

Tabel 3. Perhitungan Unit Cost pada Instalasi Rawat Jalan

\begin{tabular}{lccc}
\hline \multicolumn{1}{c}{ Keterangan } & Total Cost & Output Pelayanan & Unit Cost \\
\hline Poli Penyakit Dalam & 1.575 .803 .138 & 7.353 & $214.307,51$ \\
Poli Kandungan & 1.070 .222 .392 & 3.943 & $271.079,63$ \\
Poli Bedah & 976.080 .566 & 1.268 & $312.245,86$ \\
Poli Anak & 595.446 .627 & 1.729 & $344.387,87$ \\
Poli Mata & 209.371 .696 & 470 & $445.471,69$ \\
Poli THT & 260.074 .887 & 448 & $579.231,37$ \\
Poli Gigi dan Mulut & 254.651 .407 & 410 & $621.100,99$ \\
\hline
\end{tabular}


biaya produksi dibagi habis rata (uniformly spread) ke semua jenis produk tanpa mempertimbangkan penggunaan sumberdaya. Kondisi ini yang disebut sebagai subsidi silang (product cost cross subsidization).

Secara teoritis, dengan mengetahui unit cost dan kemampuan membayar masyarakat maka RS dapat meningkatkan pemerataan dan keadilan dengan mlihat seberapa besar subsidi dan siapa yang menikmati subsidi tersebut (Djuhaeni, 2009). Hasil perhitungan unit cost menggunakan data actual pada tabel 3 menunjukkan unit cost yang mengalami undercosting yaitu pada poli penyakit dalam dimana unit cost sebesar Rp 214.307,51. Hal ini dikarenakan denominator yang digunakan dalam penelitian ini adalah jumlah kunjungan pada poli penyakit dalam yang cukup tinggi yaitu 7.353 kunjungan tanpa memperhatikan tingkat keparahan atau jenis-jenis penyakit yang dilayani di poli penyakit dalam tersebut. Menurut Sulistyarini (2012) semakin besar output maka akan semakin rendah pula biaya satuan, sampai batas tertentu karena bila tingkat pelayanan terus ditingkatkan maka akan diperlukan tambahan faktor input.

Biaya satuan per kunjungan/pasien pada poli gigi dan mulut adalah sebesar Rp 621.100,99. Hal ini memperlihatkan kasus overcosting yang dikarenakan denominator yang digunakan adalah jumlah kunjungan di poli gigi (sebanyak 410 kunjungan), sementara pelayanan di poli gigi dan mulut jenisnya bervariasi dalari cabut gigi, scalling, tambal dan sebagainya. Apabiladata yang tersedia lebih baik dan lengkap maka perhitungan unit cost bisa di-breakdown berdarkan jenis-jenis layanan di poli gigi dan mulut. Begitu juga yang terjadi pada perhitungan unit cost lainnya.

\section{Kesimpulan dan Saran \\ Kesimpulan}

Akumulasi dan alokasi biaya pada instalasi rawat jalan di RSUD X Jambi menggunakan metode step down menunjukkan biaya satuan pada poli penyakit dalam, poli kandungan, poli bedah, poli anak, poli mata, poli THT, poli gigi dan mulut berturut-turut adalah sebesar Rp 214.307,51; Rp 271.079,63; Rp 312.245,86; Rp 344.387,87; Rp 445.471,69; Rp579.231,37 dan RP 621.100,99. Biaya satuan tertinggi terjadi di poli gigi dan mulut sedangkan biaya satuan terendah di poli penyakit dalam. Hasil perhitungan biaya satuan dilakukan secara agregat dengan membagi total cost pada masing-masing poli dan membaginya dengan jumlah kunjungan tanpa memperhatikan kasus atau penyakit yang terjadi pada masing-masing poli. Akumulasi dan alokasi biaya pada instalasi rawat jalan di RSUD X Jambi menggunakan metode step down menunjukkan biaya satuan pada poli penyakit dalam, poli kandungan, poli bedah, poli anak, poli mata, poli THT, poli gigi dan mulut berturut-turut adalah sebesar Rp 214.307,51; Rp 271.079,63; Rp 312.245,86; Rp 344.387,87; Rp 445.471,69; Rp579.231,37 dan RP 621.100,99. Biaya satuan tertinggi terjadi di poli gigi dan mulut sedangkan biaya satuan terendah di poli penyakit dalam. Hasil perhitungan biaya satuan dilakukan secara agregat dengan membagi total cost pada masing-masing poli dan membaginya dengan jumlah kunjungan tanpa memperhatikan kasus atau penyakit yang terjadi pada masing-masing poli.

\section{Saran}

Diharapkan hasil penelitian ini dapat menjadi pertimbangan dalam perubahan ataupun penyesuaian tarif layanan dan menjadikan bahan evaluasi pada poli rawat jalan agar lebih efisien dalam pengelolaanya.Tentunya ini akan menjadi tantangan bagi RS karena dalam penetapan tarif yang berlaku harus didasarkan pada perhitungan unit cost yang matang, valid dan akurat serta mempertimbangkan kemampuan dan kemauan membayar masyarakat.

\section{Referensi}

Ambarriani, A. S. 2012. Informasi Unit Cost di Rumah sakit Untuk Apa?, manajemenrumahsakit.net.

Conteh, L. and Walker, D. 2004. Cost and unit cost calculations using step-down accounting, Health Policy and Planning. 9(2) doi: 10.1093/heapol/ czh015.

Djuhaeni, H. 2009. Jasa Pelaksana Pelayanan di Rumah sakit Umum Daerah (Teori dan Praktis). Bandung.

Hansen, D. R. and Maryanne, M. 2005. Akuntansi Manajemen. 8th edn. Jakarta: Salemba Empat.

Hongren, Charles. T, Datar, Srikant M, Foster, George.2008. Akuntansi Biaya: Penekanan Manajerial; Alih bahasa Desi Ahariani. Jakarta: PT Indeks

Handayani, et al. 2018. Unit Cost Rumah sakit dan Tarif Ina-CBGs: Sudahkan Pembiayaan Pelayanan Kesehatan Rumah sakit Dibayar dengan Layak? Buletin Penelitian Sistem Kesehatan. 21 (4): 219-227.

Shepard, D. S., Hodgkin, D. and Anthony, Y. 1998. Analysis of hospital costs: a manual for manag- 
ers. Institute for Health Policy, Heller School, Brandeis University, Waltham, MA, pp. 1-85. .

Sulistyarini, Nily. Moediarso, Bendrong. 2012 Analisis Biaya Unit Pelayanan Otopsi dengan Metode Distribusi Ganda. Jurnal Kedokteran Forensik Indonesia, Vol. 14 No. 3 Juli-September.

Sugiyarti, A. T., Nuryadi and Christyana, S. 2013. Analisis biaya satuan (unit cost) dengan metode activity based costing ( $A B C)$ studi kasus di poli mata RSUD Balung Kabupaten Jember. Jurnal
Pustaka Kesehatan. 1(1), pp. 7-14.

Peraturan Pemerintah Nomor 23 tahun 2005 tentang pengelolaan keuangan badan layanan umum

Peraturan Meneri Dalam Negeri Nomor 61 tahun 2007 tentang pedoman teknis pengelolaan keuangan badan layanan umum daerah

Peraturan Daerah Kabupaten Sarolangun Nomor 32 tahun 2015 tentang perubahan atas Peraturan Bupati Nomor 56 tahun 2013 tentang tarif pelayanan kesehatan selain kelas III. 